\section{Paranoid about peer review?}

SIR - During my six years as a postdoc in England, I published a reasonable number of papers without ever having any reason to question the fairness of the peer-review system used by scientific journals. The papers just went through, some came back for alterations and that was that. Upon my return to Brazil, however, I began to experience more difficulty in getting my papers accepted by the same journals. Nowadays a manuscript almost always goes round at least twice before it gets published.

Except perhaps for the speed with which the data are generated, neither the style nor quality of the papers seems to have changed. My group continues to produce original work, scrupulously conducted and genuinely contributing to the general discussion on the theme, which has not changed either.

Could it be that papers originating from research institutions in 'developing countries', to use an accepted euphemism, are more rigorously reviewed than those from laboratories elsewhere? I think they are. This almost inescapable conclusion is reinforced by two major observations based on a pattern detected in the letters from the referees. First, they criticize the quality of the results, as in clarity of protein/DNA gels and so on, although I find no differences between what we produce and what is presented in most journals. These criticisms are usually final and leave no room for an appeal. Second, whenever there is a conflict between the referees, the editor's final decision invariably tilts towards a recommendation for rejection, rather than getting a third opinion. This happens even when the unfriendly referee does not present weighty arguments, or is obviously not familiar with the subject.

The question now arises as to the existence or not of such bias. How could one, in a true scientific manner, test this hypothesis? Separating the objective from the subjective is very difficult, but as the scientific publishing business is entirely based on peer review, it is surely worthy of discussion. I have racked my brain to come up with an experimental protocol that could confirm or dismiss my suspicions. The answer is that, short of resorting to fabricating different addresses for the same manuscript, an obviously objectionable practice, there is no simple answer.

On the other hand, if the much more esoteric problem of establishing the veracity of the Indian rope-trick can be tackled (Nature 338, 212-213; 1996), analysing prejudice in reviewing papers should be comparatively easy to establish. Taking advantage, therefore, of the fact that Nature is a high impact journal with a worldwide readership, it should be feasible and interesting to ask whether my Southern Hemisphere colleagues share my predicament. Surely the resulting opinion poll would be amenable to a proper statistical treatment? Only then would it be revealed whether the tropics have turned me into a bad scientist or just a paranoid.

\section{Franklin D. Rumjanek}

Departamento de Bioquimica Medica $I C B / C C S$,

Universidade Federal do Rio de Janeiro, Ilha do Fundao, CEP 21941-590,

Rio de Janeiro, Brazil

\section{South African priorities}

SIR - As a former policy adviser to the Department of Arts, Culture, Science and Technology, I should like to take issue with a number of the points raised in your recent Briefing on science in South Africa (Nature 384, 11-15; 1996). In particular I feel that the article fails adequately to reflect the inherently weak position from which the scientific community starts in its attempts to achieve extra funding. This has little to do with the political allegiance of the minister concerned, but more with perceptions of what South African science has delivered in the past, and what it might deliver in the future. To imagine that the Ministry of Finance would reverse its policy on tax breaks at the behest of the science community is wishful thinking indeed.

Comments about South African science based on citation counts miss the important fact that some citations are inevitably inflated by publications on research aspects of South Africa's natural environment. It is obviously easier for a local researcher to write a paper on a unique indigenous species (and of course to research it well) than someone abroad.

Furthermore, while it is true that science funding of $\$ 23$ per capita is high for a newly industrializing country, when corrected for the fact that this science is conducted by the 'first world' component of the country, spending is actually commensurate with that of Australia, Spain or New Zealand. When the scientific community is asked how it performs in comparison to those countries, the answer is: not very well.

Ultimately the funding debate will turn - perhaps erroneously - on perceptions of value for money. The department does not need convincing about the need to identify priorities, as it has advocated this since its establishment. In contrast, those who need to absorb this message are the universities, which cling to notions of academic freedom, and research councils, which are trying to prove that their activities are already socially attuned.

\section{Michael Kahn}

PO Box 1833,
Houghton 2041, South Africa
Mote and beam

SIR - David Edge, the Editor of Social Studies of Science complains (Nature 384, $106 ; 1996)$ of recent attacks against the sociology of science using rude language and intemperate tone. He should have said more precisely against the 'sociology of scientific knowledge' (SSK) the fashionable school of sociology of science that came to dominate his journal. There were no such attacks against the older Mertonian school.

Browsing through the 25-year-old volumes of Social Studies of Science (in which the following references appear), I have found plenty of anti-scientist polemics and intemperate language in papers by SSK-ists. For example S. Fuller called scientists "knowledge-mongerers" (19, 397; 1989) who deal with a "corrupt realm of privileged objects". Steven Weinberg, the Nobel-prizewinning theoretical physicist and science administrator was called a "megalomaniac" (24, 157; 1994). Another Nobel prizewinner, Herbert Simon, was characterized as revealing "a muddled grasp of the methatheoric issues surrounding his own work" and accused of joining the dispute on computer simulation of discovery because "it must be grant renewal time" (21, 149; 1991). A similar charge was addressed to Weinberg and his "elite scientist friends" for using rhetoric to justify spending billions of dollars. Noam Chomsky, the world-famous linguist, was called an "upstart linguist" and blamed for "cognitive chauvinism" $(19,629 ; 1989)$.

Scientists are like "high priests" $(14,483$; 1984), they present themselves like God but they are more like the devil (the latter is not original: William Blake was the first to depict Newton as the devil!). Another author characterizes the opposing camps as "us", social scientists = civilized human beings, versus "them", knowledge engineers = primitive savages $(\mathbf{2 4}, 106 ; 1994)$. Edge talks about close collaboration with scientists. He has a point: unlike Merton, Kuhn and Popper, the SSK-ists did go into the laboratories, did observe how everyday science was carried out and to that extent collaborated with the-scientists. As elsewhere in anthropology, it would be too much to expect contributions by the 'natives' in the opinions expressed.

There was one occasion when a scientist was given a voice explicitly; Jonas Salk wrote the introduction to the book by B. Latour and S. Wolgar (Laboratory Life: The Social Construction of Scientific Facts, Princeton, 1986). He expressed his doubts about SSK and stressed that many details of his own work did not fit. Such opinion would probably be typical of those scientists who collaborated in the SSK fieldwork. Perhaps it is time to stop the unscholarly behaviour on both sides.

George Magyar

31 South Avenue

Abingdon, Oxon, UK 